\title{
Cell biology of spinal cord injury and repair
}

\author{
Timothy M. O'Shea, Joshua E. Burda, and Michael V. Sofroniew \\ Department of Neurobiology, David Geffen School of Medicine, UCLA, Los Angeles, California, USA.
}

\begin{abstract}
Spinal cord injury (SCI) lesions present diverse challenges for repair strategies. Anatomically complete injuries require restoration of neural connectivity across lesions. Anatomically incomplete injuries may benefit from augmentation of spontaneous circuit reorganization. Here, we review SCI cell biology, which varies considerably across three different lesionrelated tissue compartments: (a) non-neural lesion core, (b) astrocyte scar border, and (c) surrounding spared but reactive neural tissue. After $\mathrm{SCI}$, axon growth and circuit reorganization are determined by neuron-cell-autonomous mechanisms and by interactions among neurons, glia, and immune and other cells. These interactions are shaped by both the presence and the absence of growth-modulating molecules, which vary markedly in different lesion compartments. The emerging understanding of how SCI cell biology differs across lesion compartments is fundamental to developing rationally targeted repair strategies.
\end{abstract}

\section{Introduction}

Spinal cord injury (SCI) is a major cause of long-term physical impairment. Current treatments are limited mostly to supportive measures. Affected individuals often have life expectancies of decades with permanent disability (1-3). To develop appropriately targeted repair strategies, there is a need for a better understanding of the broad cell biology of SCI and how that cell biology differs in different SCI lesion compartments. Normal function in the CNS requires interactions of many cell types, including neurons, neuroglia, and non-neural cells (4). Similarly, the response to CNS injuries involves complex multicellular interactions, and the activities of diverse cell types can influence SCI outcome (5). Here, we review current information and highlight critical gaps in knowledge about (a) the cellular organization of SCI lesions, (b) mechanisms that regulate circuit reorganization and axon regrowth after SCI, and (c) specifically targeted repair strategies.

\section{Formation of $\mathrm{SCl}$ lesions}

Most human SCI lesions result from mechanical traction and compression forces secondary to acute crush, penetrating injury, or long-term compression, caused by displaced bone, bone fragments, or disc material $(1,6)$. Hemorrhage and ischemic damage are prominent features. Lesions can be grouped into major subtypes: (a) microscopic damage with normal gross anatomy, (b) contusions with multifocal areas of hemorrhage and necrosis that convert to connective tissue scar, (c) lacerations from penetrating injury by bony fragments or foreign bodies, (d) crush and compression injuries with large areas of non-neural connective tissue scar, and (e) fluid-filled cysts that replace lost tissue (6).

\section{Compartmental organization of SCI lesions}

Regardless of cause or size, mature SCI lesions can be divided into three tissue compartments that each have a unique cell biology: (a)

Conflict of interest: The authors have declared that no conflict of interest exists. Reference information: / Clin Invest. 2017;127(9):3259-3270.

https://doi.org/10.1172/JCI90608. a central non-neural lesion core, often referred to as fibrotic scar (also mesenchymal or connective tissue scar); (b) an astroglial scar border that intimately surrounds the lesion core; and (c) a surrounding zone of viable neural tissue that is spared and functional but reactive and is demarcated by the presence of reactive glia (Figure 1 and ref. 5). These three compartments exhibit markedly different cellular composition and functional interactions.

Non-neural lesion core. Cell damage after SCI is mediated by physical forces, metabolic damage, and ischemia. Cellular debris can be toxic (7). Multiple mechanisms balance debris clearance and sparing of potentially functional adjacent neural tissue. Specific molecular cues label damaged cells for clearance or label healthy cells for sparing (7). Innate inflammatory responses implement debris clearance. Microglia and astrocytes are local tissue resident cells that are early responders with limited phagocytic capacity and the ability to elaborate growth factors, cytokines, and chemokines to recruit professional blood-borne inflammatory cells to assist with debris clearance. These mechanisms must be balanced because too little inflammation can lead to accumulation of cytotoxins, whereas too much inflammation can destroy tissue (5). Perivascular fibroblast-derived stromal cells, meningeal fibroblasts, and pericytes (8-10) proliferate markedly in lesion cores. As cellular debris are cleared and lesion cores mature, they become composed primarily of these stromal non-neural cells intermingled with endothelial progenitors and newly formed blood vessels, as well as with extravasated blood-borne cells such as fibrocytes and diverse immune cells, including hematogenous macrophages, neutrophils, lymphocytes and other leukocytes (which change over time), as well as substantial extracellular matrix components (Figure 1, A and $\mathrm{B}$, and ref. 5). Over time, blood-borne inflammatory cells normally recede; however, their prolonged persistence can be associated with increased tissue damage $(11,12)$.

Astrocyte scar border. Starting 1 to 2 days after SCI and continuing for about 7 to 10 days, astrocytes proliferate and organize around the edges of severely damaged and unsalvageable tissue (13). These newly proliferated astrocytes migrate, intertwine their pro- 
A

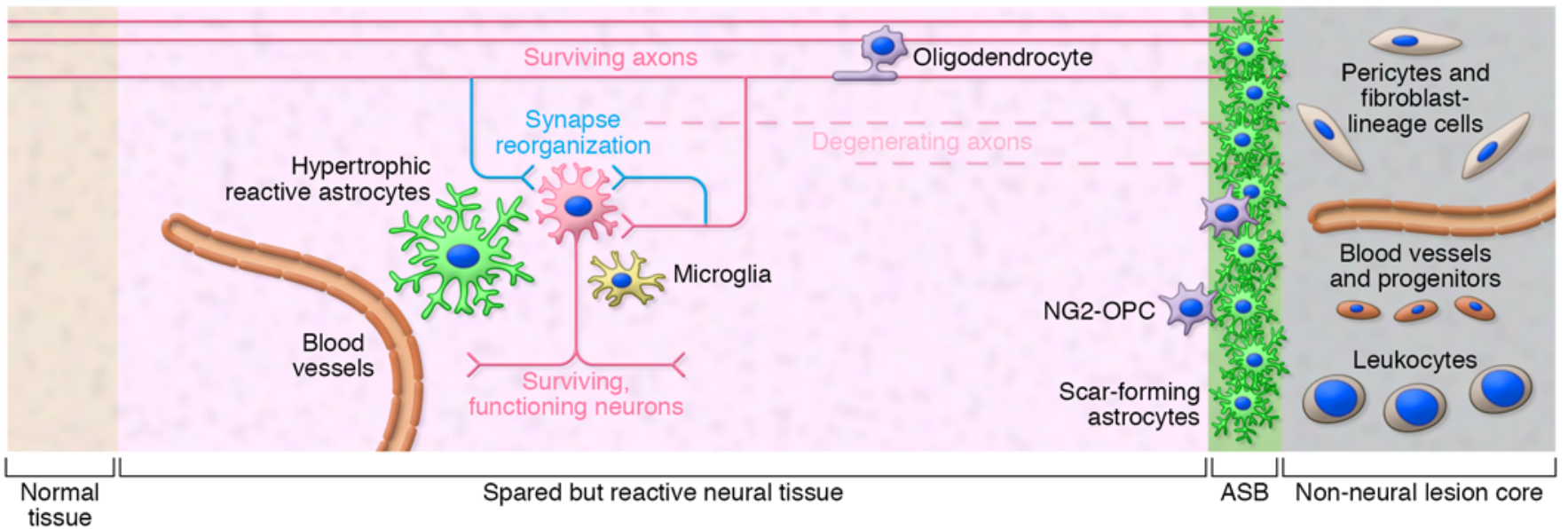

B

Spared but reactive neural tissue ASB Non-neural lesion core
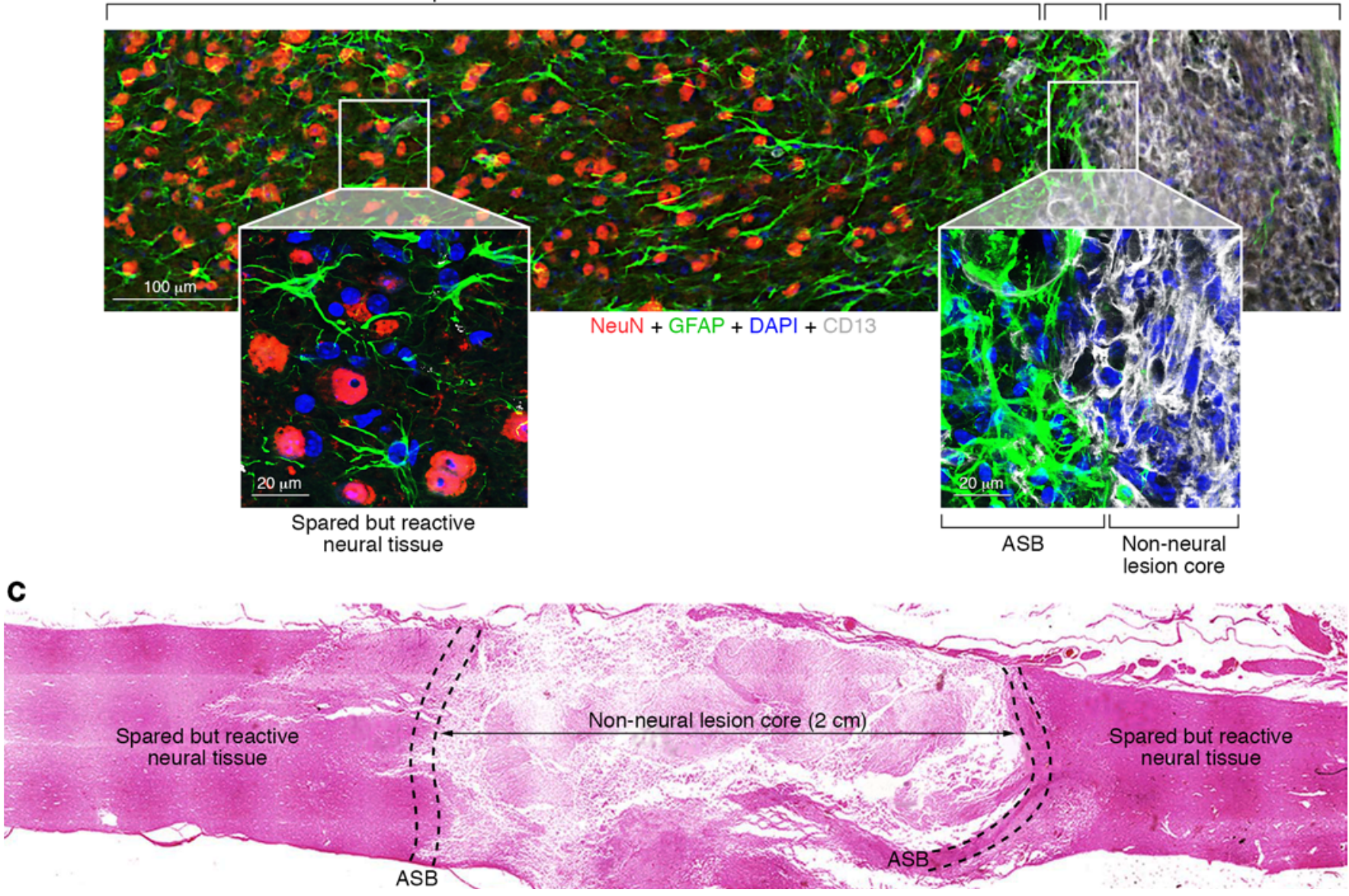

Figure 1. SCI lesions exhibit discrete tissue compartments. (A) Schematic of SCI lesion compartments composed of different neural and non-neural cells. (B) Photomicrograph showing different cellular components in discrete tissue compartments of a mouse severe crush SCI (T9-T10) lesion. Boxed areas are enlarged to show details. Astrocytes are stained green using glial fibrillary acidic protein (GFAP). Neurons are stained red using NeuN. Pericytes and fibroblast-lineage cells in lesion core are stained white using CD13. Cell nuclei are stained blue using DAPI. (C) Survey photomicrograph of human severe $\mathrm{SCI}(\mathrm{C5}-\mathrm{C7})$ showing relative proportions of lesion compartments (reproduced with permission from Brain, ref. 11). OPC, oligodendrocyte progenitor cell; ASB, astrocyte scar border.

cesses, and assemble into a scar border around inflamed non-neural lesion core tissue (Figure 1, A and B, and refs. 5, 13). This scar border formation is complete by 2 to 3 weeks after SCI and consists almost entirely of newly proliferated astrocytes $(13,14)$. Astrocyte scar borders have structural and functional similarities to the glia limitans borders formed by astrocytes along all meningeal surfaces and blood vessels in the healthy CNS, which also separate neural from non-neural tissue (15). Functionally, astrocyte scar borders 
corral inflammatory cells within areas of damaged tissue $(13,15)$ and protect adjacent viable neural tissue, such that their loss or dysfunction leads to increased spread of destructive inflammation, resulting in larger lesions and worse functional outcome $(13,15-18)$. Like glia limitans borders along meninges, astrocyte scar borders are narrow and only several cell layers thick (Figure 1, A and B) (13, 15). For this reason, the proportion of astrocyte scar to lesion core volume is often small, particularly in human SCI lesions (Figure 1C) (6). Astrocyte scar borders are intermingled with reactive oligodendrocyte progenitor cells (OPC) that express chondroitin sulfate proteoglycan 4 (also known as neuron glial antigen 2 [NG2]), and these cells are often referred to as NG2-OPC (Figure 1A). The lineage derivation of newly proliferated scar-forming astrocytes is not completely defined, but many if not most appear to derive from proliferation of local astrocytes (17) and not from putative ependymal progenitor cells (14). Genomic profiles of astrocytes and nonastrocyte cells in mature SCI lesions have recently been evaluated by RNA sequencing (19), and data for individual genes are available in a searchable open-access website (https://astrocyte.rnaseq. sofroniewlab.neurobio.ucla.edu).

Spared but reactive neural tissue. Astrocyte scar borders are directly continuous with, and are surrounded by, an outer zone of spared but reactive neural tissue containing all elements found in normally functioning neural tissue (Figure 1, A and B, and ref. 5). This tissue extends away from the lesion core and its astrocyte scar border in all directions and can be surprisingly large (Figure $1, \mathrm{~B}$ and $\mathrm{C})$. It is characterized by the presence of reactive glia, including astrocytes, microglia, and NG2-OPCs, whose hypertrophy and other reactive changes taper in a graded fashion that diminishes with distance from the lesion core (Figure $1 \mathrm{~B}$ and ref. 5). Notably, hypertrophic reactive astrocytes in spared but reactive neural tissue retain their interactions with functioning neurons. These hypertrophic reactive astrocytes are fundamentally different, both phenotypically and functionally, from newly proliferated astrocytes that form the narrow scar borders around non-neural lesion cores (Figure 1B and ref. 20). This spared but reactive tissue is undergoing substantial synapse turnover and circuit reorganization as discussed below.

\section{Anatomically complete or incomplete SCI lesions}

SCI lesions and their different compartments present diverse challenges for repair strategies. Anatomically complete lesions will require restoration of neural connectivity across large and hostile non-neural lesion cores (Figure 1C), whereas anatomically incomplete injuries may benefit from augmentation of spontaneous circuit reorganization in spared but reactive neural tissue (Figure 1A). Anatomically complete SCI can be caused by single large lesions or multiple small lesions that span the entire spinal cord and result in the complete absence of neural connectivity across the lesion site (Figure 2A). Anatomically complete $\mathrm{SCI}$ is functionally complete, in that no voluntary motor control or sensory perception is conveyed across the lesion. Anatomically incomplete SCI can be formed by one or more smaller lesions that spare sufficient neural tissue so as to preserve or allow the spontaneous re-formation of some neural connectivity across the lesion site, either directly from supraspinal sources or indirectly via propriospinal neurons (Figure 2A). Anatomically incomplete SCI can be associated with varying degrees of preserved or restored functions, or can be functionally complete in situations where neural connections may be present but are insufficient to mediate functions.

\section{Spontaneous circuit reorganization occurs after all SCl}

Fifty years ago, Raisman first showed that after injury-induced loss of one set of synaptic inputs to a forebrain region, new synapses are spontaneously formed by surviving local terminals derived from a different set of inputs (21). It is now clear that this type of synapse and circuit reorganization occurs spontaneously after all forms of CNS injury, including after SCI, and that it can be associated with either adaptive or maladaptive functional changes. After anatomically complete or incomplete SCI, synapse loss is prominent in spared but reactive neural tissue, and this synapse loss spontaneously leads to new synapse formation that can derive from different sources, including immediately local surviving terminals or sprouting of more distant axons (Figure 1A; Figure 2, A and B; and refs. 22-24). In some cases, spontaneous synapse turnover and circuit reorganization can lead to maladaptive consequences such as muscle spasticity (25), autonomic dysreflexia (26), or neuropathic pain $(27,28)$. In other cases, spontaneous circuit reorganization can be adaptive and restore function after incomplete SCI, as in the spontaneous bilateral locomotor recovery that occurs after unilateral hemisection SCI (Brown-Séquard syndrome) in spite of permanent loss of descending supraspinal connections on the injured side $(23,24,29-32)$. Dissecting underlying cellular and molecular mechanisms and learning how to beneficially modulate spontaneous adaptive or maladaptive circuit reorganization are important targets for SCI research.

\section{Distinguishing axon regeneration, local sprouting, and synapse plasticity}

Axon responses to CNS injury are often referred to simply as degeneration or regeneration. However, it is important to delineate multiple forms of potential axon responses $(33,34)$, which are summarized here as (a) axon degeneration and retraction, (b) axon regeneration attempts across non-neural lesion core, (c) axon regeneration from transected ends through spared reactive neural tissue, (d) axon sprouting of branches that grow through spared neural tissue, and (e) local synaptic plasticity in spared neural tissue (Figure 2B). Effective treatment strategies will need to be based on an understanding of how different forms of axon growth are regulated by different specific molecular mechanisms in different lesion compartments.

\section{Diverse regulation of axon growth and synapse remodeling}

Multiple factors regulate axon growth and synapse formation after SCI, including neuron-cell-autonomous mechanisms, effects mediated by other cells, and the presence or absence of various molecular signals. Although the notion of environmental axon growth inhibition has received much recent attention, mounting evidence indicates that axon growth and circuit repair are regulated as much, or more, by neuron-cell-autonomous mechanisms, access to essential growth-promoting factors, and other regulatory mechanisms. 
A

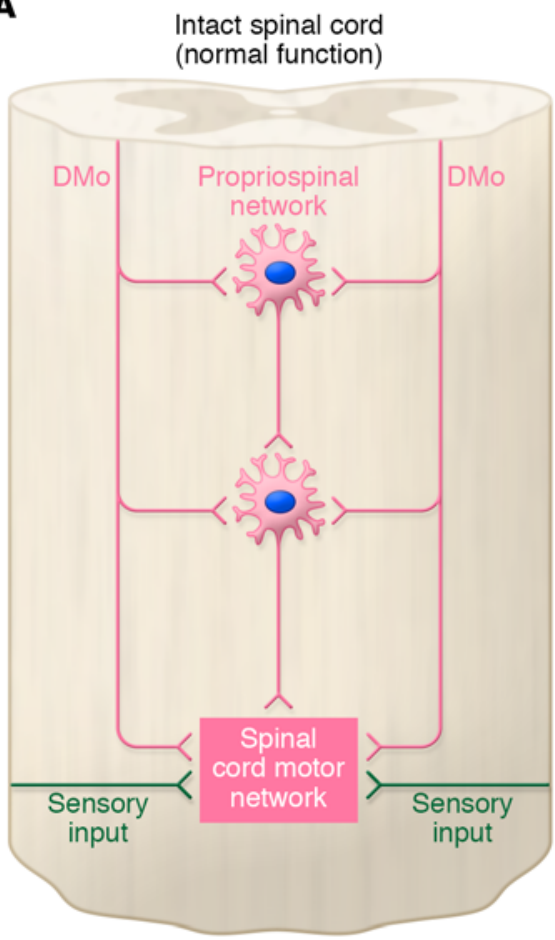

Anatomically complete SCI (no function, maladaptive effects)

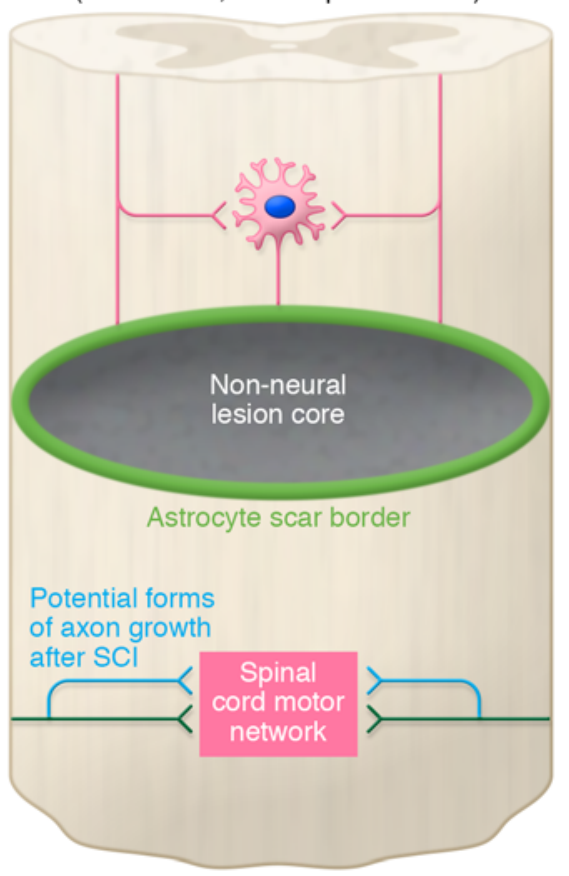

Anatomically incomplete SCI (partially restored function)

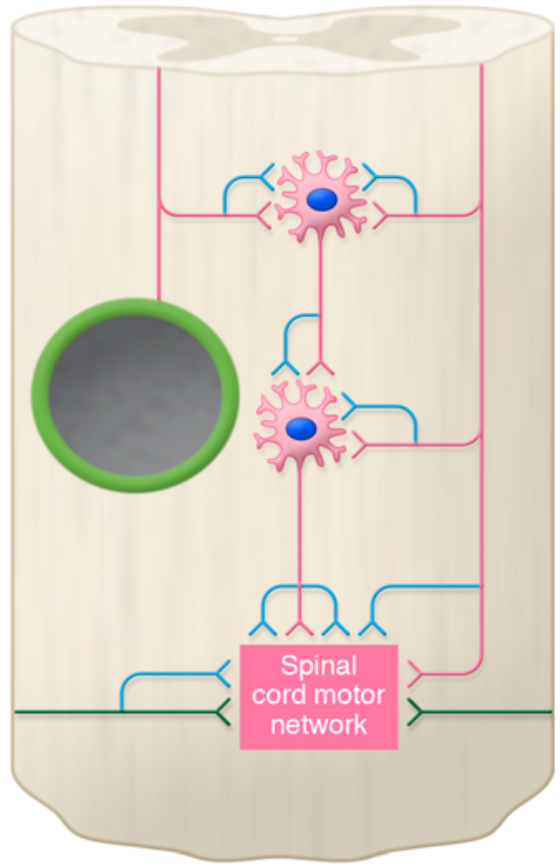

B
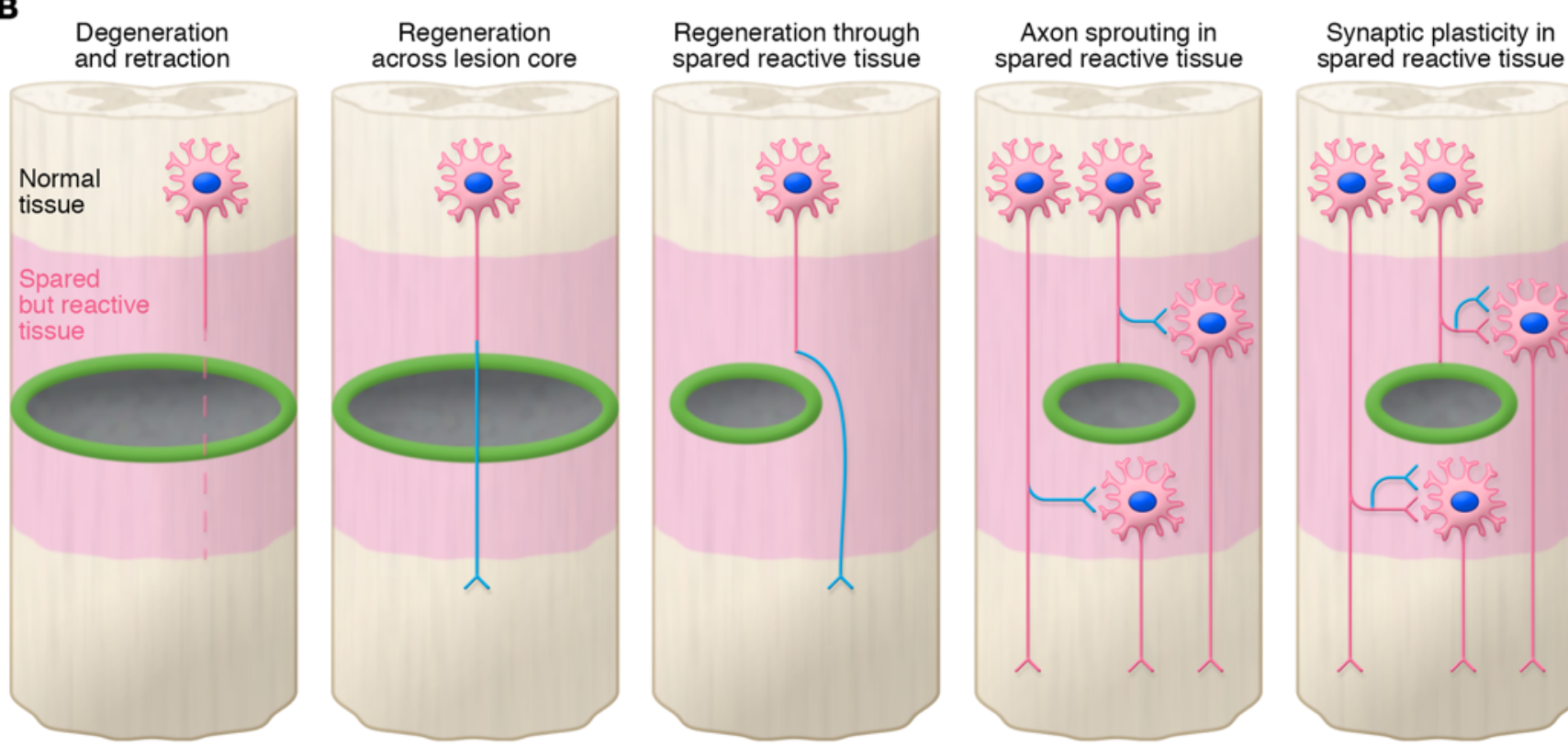
spared reactive tissue

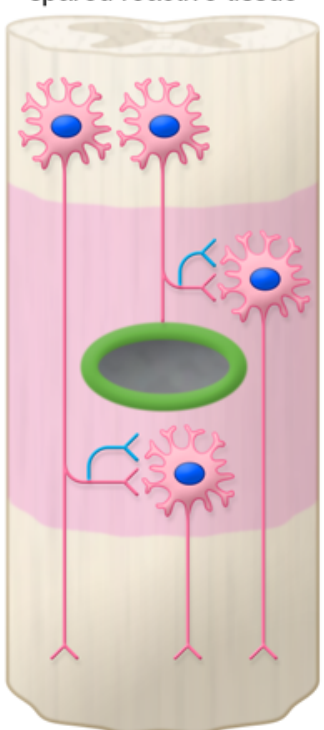

Figure 2. Circuits reorganize after SCI. (A) Different types of circuit reorganization after different types of SCl. Anatomically complete SCl is associated with synaptic plasticity that can give rise to maladaptive effects such as muscle spasticity or autonomic dysreflexia. Anatomically incomplete $\mathrm{SCl}$ can also give rise to axon growth and synaptic plasticity that can partially restore function. (B) Different potential growth responses of axons and synapses after $\mathrm{SCl}$. DMo, descending motor projections.

Neuron-cell-autonomous regulation of axon growth. During development, CNS neurons exhibit robust axon growth; but even during development axons do not grow by default and require environmental factors that attract and support growth $(35,36)$. CNS neurons lose their intrinsic capacity to grow axons as they mature $(36,37)$ and exhibit poor reactivation of intrinsic programs for axon growth after injury (38). Transected adult CNS axons exhibit poor spontaneous formation of new growth cones $(38,39)$. Neuron-intrinsic mechanisms regulating the capacity to regrow injured axons are being dissected. Early studies showed that transected CNS branches of sensory neurons are 100 times more likely to grow into peripheral nerve grafts after SCI if their peripheral branches have been cut previously by so-called priming injuries (40). Such priming injuries also trigger some sensory 
axon regeneration through SCI lesions (41). Stimulation of sensory neurons with cAMP mimicked priming injury effects (42-44). Ground-breaking work from Zhigang He and colleagues showed that signaling through PTEN, mTOR, STAT3, and SOCS3 pathways intrinsically regulates the axon-regenerative capacity of mature retinal and corticospinal neurons $(38,45-47)$. Additional neuron-intrinsic regulators of axon regrowth are depicted in Figure 3A $(38,48-51)$.

Multicellular influences on axon regrowth. Multiple cell types influence axon regrowth after SCI, including astrocytes, NG2OPCs, fibroblast-lineage cells, microglia, hematogenous macrophages, and other immune cells. Different cell types are present in different lesion compartments. Many molecular regulators are produced by multiple cell types.

Astrocytes are present in two SCI lesion compartments, scar borders and spared but reactive tissue. Astrocyte phenotype and function differ fundamentally in these two compartments (20). Scar-forming astrocytes are almost all newly proliferated, do not exhibit individual domains, and intertwine to form glia limitans borders that restrict inflammation and separate non-neural lesion core from adjacent functioning neural tissue (refs. 13, 15, 52, and Figure 1, A and B). Scar-forming astrocytes were long thought to be the primary cause for the failure of CNS axons to regenerate $(53,54)$, but this notion is now strongly challenged by studies showing that appropriately stimulated CNS axons regenerate robustly in spite of astrocyte scar formation in optic nerve $(45,47$, 55 ) and in spinal cord (19). Neither preventing astrocyte scar formation nor removing chronic astrocyte scars leads to spontaneous axon regeneration of descending motor, ascending sensory, or serotonin axons (19). Scar-forming astrocytes express the axon growth-supporting matrix protein laminin $(19,56)$, and antibody blockade of laminin-integrin binding attenuates stimulated axon regeneration after SCI (19). Mature injured CNS axons regrow along astrocytes after CNS injury when stimulated by appropriate growth factors (57) or by genetic activation (58). Grafts of progenitor-derived astrocytes support axon regeneration though SCI lesion cores (59-61). Targeted disruption of astrocyte scar formation attenuates stimulated axon regeneration after SCI (19). Axons grow along astroglia during development (62-64). Spontaneous axon regeneration after SCI in lower vertebrates occurs along astroglial bridges formed in response to connective tissue growth factor (65). Thus, astrocyte scars may aid rather than hinder axon regeneration (19).

Reactive astrocytes in spared tissue of SCI lesions differ fundamentally from scar-forming astrocytes. They are nonproliferative and hypertrophic, maintain their basic structure and individual domains, and interact functionally with neurons and synapses (ref. 20 and Figure 1, A and B). Emerging evidence suggests that these hypertrophic reactive astrocytes are critically involved in inducing local axon sprouting and regulating synapse plasticity and circuit reorganization (Figure $3 \mathrm{~A}$ and discussed below).

NG2-OPCs are glial cells with progenitor potential and other functions $(66,67)$. After CNS injury, NG2-OPCs are present in two compartments, scar borders and spared reactive neural tissue (Figure 1A and Figure 3A). In scar borders, NG2-OPCs are hypertrophied and are reported to restrict axon dieback and axon regrowth (68-70). Other reports show that robust axon growth can be stimulated through areas of dense NG2 in vivo $(71,72)$, NG2OPCs robustly support axon regrowth (73), and deletion of NG2 fails to increase spontaneous axon growth in vivo (74). Thus, with respect to axon regrowth after SCI, the roles of NG2-OPCs and of NG2 are not fully understood.

Pericytes and fibroblast-lineage cells are major components of non-neural lesion core (Figure 1A, Figure 3A, and refs. 8, 9). Molecules produced by these cells have axon-inhibitory properties in vitro, including certain collagens and chondroitin sulfate proteoglycans (CSPGs) (75). Nevertheless, failure of axon regrowth through lesion core may depend as much on the absence of required growth-stimulatory chemoattractive molecules as on the presence of putative inhibitors. For example, fibroblast cell grafts support robust axon regeneration after SCI but do so only when they produce specific axon-stimulatory growth factors (76). Growth factors required for sensory axon growth during development are absent from SCI lesion core, and delivery of those growth factors via biomaterial depots attracts substantive sensory axon regrowth into SCI lesion cores (19).

Immune and inflammatory cells also influence regrowth of injured CNS axons. Activated macrophages induce retraction and dieback of axons after SCI (77). In contrast, neutrophils around neuronal cell bodies can stimulate axon regeneration (78). More work is needed on understanding how inflammatory cells influence axon regrowth.

Environmental molecular regulators of axon regrowth. Developmental axon growth and guidance are regulated by four main types of environmental molecular cues: diffusible chemoattraction, contact chemoattraction, diffusible chemorepulsion, and contact chemorepulsion (79). Similar environmental cues influence axon regrowth after SCI (ref. 80 and Figure 3A). Notably, the effects of certain cues are context-dependent and can be modified by receptor-mediated signaling in growth cones that changes responses from repulsion to attraction or vice versa $(81,82)$. Both the presence and absence of molecular cues can influence axon regrowth capacity.

Diffusible chemoattraction was first implicated in regulation of CNS axon regeneration by Cajal and Tello, who showed that (a) transected CNS axons would regrow into peripheral nerve grafts, (b) killing cells in the grafts with chloroform prevented CNS axon regeneration into them, and (c) chemical extracts obtained from peripheral nerves and loaded into cellulose matrix attracted CNS axon regrowth in vivo (see pages 388-392 and 742-750 in ref. 83). Based on these observations, Cajal theorized that in contrast with developing CNS and injured peripheral nerves, the injured adult CNS lacked diffusible chemoattractants required to promote axon regrowth. Modern axon-tracing technologies confirmed both that CNS axons regrow into peripheral nerve grafts $(84,85)$, and that this regrowth is critically dependent on neurotrophic factors produced by live cells in grafts $(86,87)$. Freezing nerves and killing resident cells prevented CNS axon growth into them, and injection of nerve growth factor (NGF) into frozen grafts restored their ability to attract regeneration of NGF-sensitive CNS axons, showing that permissive matrix alone is not sufficient for regrowth $(86,87)$. Numerous subsequent studies show that delivery into SCI lesions of developmentally active neurotrophins such as brain-derived neurotrophic factor 
A

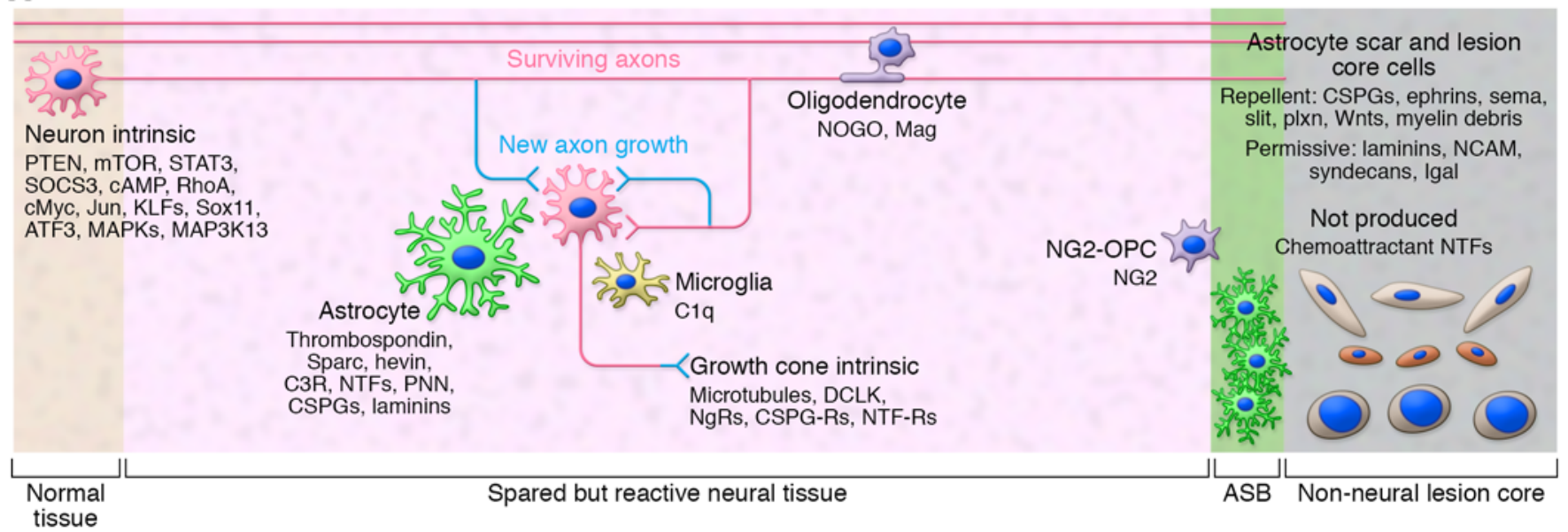

B

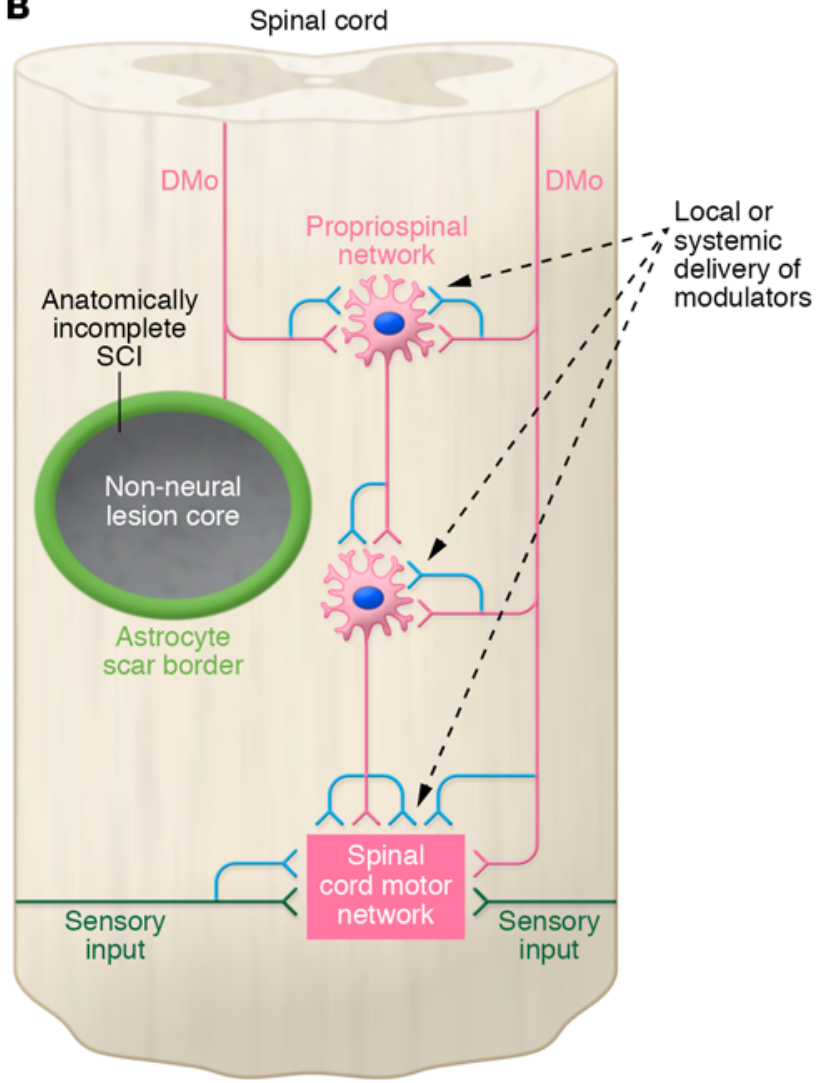

C

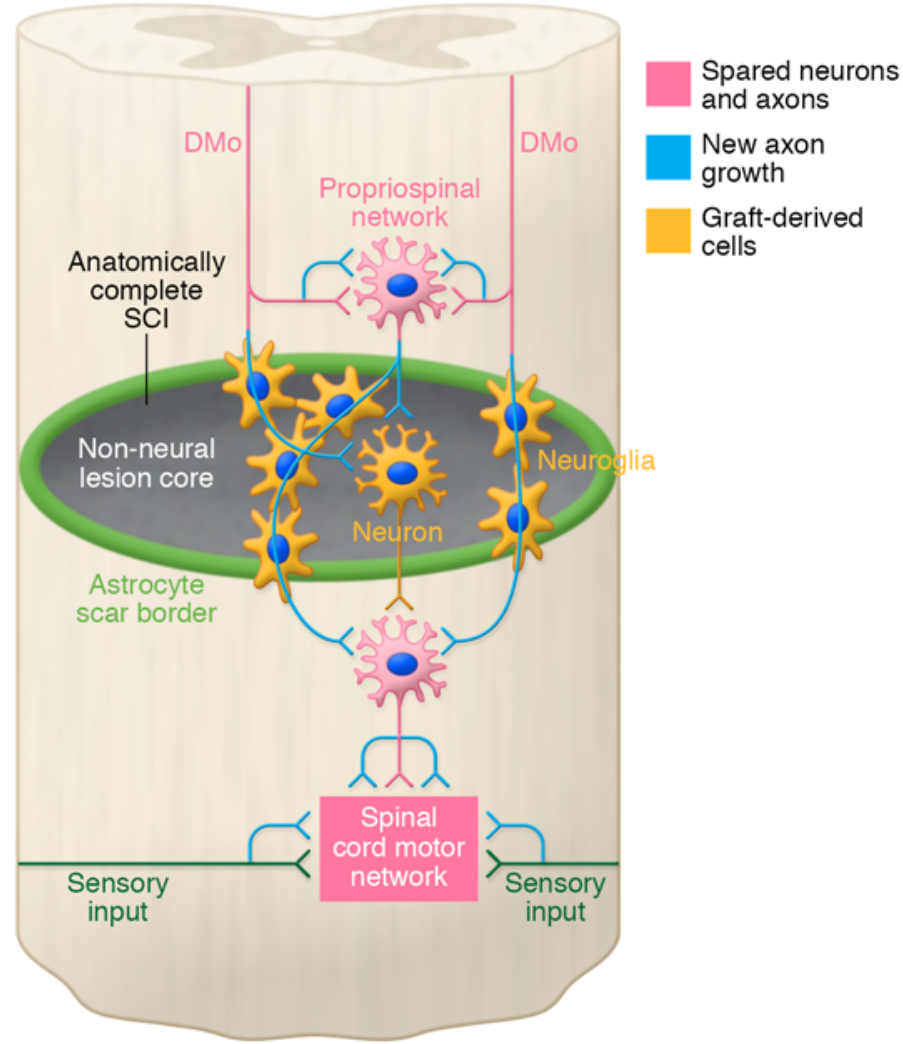

Figure 3. Growth potential of axons and synapses after $\mathrm{SCl}$ can be regulated by diverse cells and molecules in different lesion compartments. (A) Multiple cell types and molecules can influence and regulate the growth potential of axons and synapses in different lesion compartments. (B) Modulation of axon sprouting, synapse plasticity, or synapse function in spared but reactive and reorganizing neural tissue by delivery of molecules that modify perineuronal net, synapse formation, or synaptic transmission. (C) Transplantation to repopulate non-neural lesion core with neural cells that either provide new relay neurons, or provide neuroglia that support host axon regrowth, to restore circuit connectivity across the lesion. CSPG-Rs, CSPG receptors; KLFs, Krüppel-like factors; NgRs, NOCO-receptor; PNN, Peri-Neuronal-Net; NTFs, neurotrophic factors; NTF-Rs, neurotrophic factor receptors.

(BDNF), neurotrophin-3 (NT3), glia-derived neurotrophic factor (GDNF), and others, which are not detectably produced in the lesions, will promote injured axon regrowth in an axon-selective manner $(19,88,89)$. Such findings highlight the importance of the absence of required chemoattractive molecules in the failure of spontaneous axon regeneration after CNS injury.
Contact chemoattraction or growth support is mediated by molecular families such as laminins, syndecans, and heparan sulfate proteoglycans (19, 90-93). During development, axon growth on substrates is determined by combinatorial mixtures of attractive and repellent molecules, and gradients of such mixtures guide growth directionality $(79,94)$. The degree of growth 
support is determined by relative proportions of attractive and repellent molecules, such that increasing the concentration of one type of cue can overcome the effects of another $(94,95)$. Blockade of laminin-integrin interactions can prevent axon growth in vitro (90) and axon regeneration stimulated in vivo after SCI (19).

Diffusible chemorepulsion is mediated by Wnt signaling, semaphorins, netrins, and other molecules that create gradients during development $(93,96)$. Interestingly, semaphorins and netrins can be either repellent or attractive to different axons or even to the same axons depending on combinatorial signaling in growth cones $(81,82,93)$. Roles of these molecules after SCI are being studied $(93,96,97)$. Removal of semaphorins alone or in combination with removal of putative myelin inhibitors is insufficient for spontaneous regrowth of serotonin axons after SCI (98).

Contact chemorepulsion and growth inhibition of injured axons have been studied extensively, in particular as regards myelin-associated molecules (99) and CSPGs (54). The ability of these molecules to inhibit or repulse axon growth is clearly potent in vitro $(95,100)$. Nevertheless, their roles in vivo in the injured CNS with respect to different forms of injury-induced axon growth (Figure 2B) are less clearly defined and are being refined as experimental tests become more focused. Their effects on local synapse plasticity may be more relevant than effects on axon regrowth across lesions. For example, aggrecan, the prototypical CSPG used to demonstrate axon-inhibitory effects in vitro $(95,101)$, is not detectably present in SCI lesion core or astrocyte scar, but it is heavily present in perineuronal nets in spared and reorganizing neural tissue, where it may restrict synaptic plasticity $(19,102-104)$. Although NG2 (encoded by Cspg4) can inhibit axon growth in vitro, multiple in vivo studies show that robust axon regrowth occurs in the presence of NG2 and that deletion of Cspg4 does not induce spontaneous axon regeneration (71-74). Digestion or blockade of CSPGs does not reproducibly enable spontaneous axon regrowth across anatomically complete SCI lesions with non-neural lesions cores. Deleting or blocking myelin is not sufficient to enable long-distance axon regrowth across severe SCI lesions and non-neural lesion cores $(98,105,106)$. Thus, beneficial behavioral effects reported after blocking of either myelin-associated growth inhibitors or CSPG signaling are likely to be related to effects on synaptic plasticity and circuit reorganization after incomplete SCI (Figure 3B) rather than to enabling of axon regrowth across anatomically complete SCI $(99,102,104,107,108)$. It also should be emphasized that molecular cues are not absolute, such that exposure to specific growth factors can reprogram growth cones to ignore inhibitory cues both during development and after injury $(42,43,82)$. These observations highlight the importance of understanding the cell biology and molecular mechanisms regulating different forms of axon growth in different lesion compartments when interpreting behavioral observations and developing therapeutic strategies.

Multicellular and multimolecular regulation of synapse reorganization. As discussed above, trauma-induced synapse loss in spared but reactive CNS tissue spontaneously leads to formation of new synapses derived either from local surviving terminals or from more distant axons (Figure 1A, Figure 2, and Figure 3A). This spontaneous injury-induced synapse plasticity can be associated with either adaptive or maladaptive effects, both of which represent important therapeutic targets. Understanding of the underlying cellular and molecular mechanisms is being facilitated by studies of synapse development that have identified critical roles for microglia and astrocytes, and for matrix molecules of the perineuronal net.

Microglia remove synapses from neurons responding to distant retrograde or anterograde injury (109). During development, microglia help sculpt postnatal circuits by pruning supernumerary synapses as regulated by classical complement signals, C1q, C3, and C3R (110-112), and the fractalkine receptor CX3CR1 (113). Related mechanisms regulate synapse turnover in adulthood, and under conditions of disease and trauma (112).

Astrocytes extend fine processes that interact with all synapses and exert activities critical for normal synapse and circuit function $(20,114)$ and in circuit development $(114,115)$, where they secrete thrombospondins, glypicans, and hevin to promote synapse formation and activity (116-120); release the diffusible axon guidance cue semaphorin-3a, to regulate axon targeting (121); express phagocytic machinery for synapse pruning (122); and deposit extracellular matrix proteins, including tenascins and sulfated proteoglycans, which contribute to plasticity-restricting perineuronal nets (104). Increasing evidence links equivalent mechanisms to synapse plasticity and circuit reorganization after SCI, brain injury, and stroke. Hypertrophic astrocytes closely intermingle with viable neurons in spared but reactive tissue (refs. 5, 13, 123; Figure 1, A and B; and Figure $3 \mathrm{~A}$ ), where they may influence axon sprouting and synapse plasticity by modulating expression of perineuronal net-associated proteins such as neurocan and tenascin-C $(124,125)$ or by producing thrombospondin (126).

The perineuronal net, composed of matrix molecules including multiple CSPGs and tenascins, constrains synaptic plasticity and circuit reorganization $(102,104)$. During postnatal development, the perineuronal net is involved in closing critical periods of synaptic plasticity, such that enzymatic digestion of the perineuronal net by chondroitinase can reopen that plasticity $(104,127)$. Signaling related to NOGO (also known as reticulon 4 [RTN4]) and its receptors is also implicated in restricting synaptic plasticity via perineuronal net molecules during development and after injury $(99,102)$. Increasing evidence suggests that beneficial effects of blocking CSPGs or NOGO receptors after incomplete SCI are related to effects on perineuronal nets and synaptic plasticity in spared but reactive neural tissue $(99,102,108)$ rather than axon regeneration across lesions.

\section{Repair strategies}

Developing reliable repair strategies will require understanding how potential interventions influence the cell biology of different SCI lesion compartments. The requirements to beneficially modulate synaptic plasticity in spared but reactive neural tissue (Figure 3B) will differ substantively from the requirements to bridge new axon growth across non-neural lesion cores of anatomically complete lesions (Figure 3C). Different cellular and molecular targets are now under investigation to improve outcome after SCI by providing tissue protection, modulating circuit reorganization, or regulating neural bridging connectivity across lesions. 
Neuroprotection and control of inflammation. Damage caused by initial physical forces and anoxia may be beyond protective intervention. However, subacute phases after SCI may be amenable to delayed protective interventions that target and control peripheral infections and other peripheral sources of circulating inflammatory stimuli. Epidemiological studies show that comorbid infections such as pneumonia worsen functional outcome after human SCI (128-130). Potential cellular mechanisms may involve prolonged inflammation at the lesion site that results in increased tissue damage. Circulating microbial signaling molecules such as LPS can influence CNS glia and markedly alter their transcriptional profiles toward neurotoxic phenotypes $(131,132)$. After SCI, peripheral infections or other sources of inflammation may give rise to blood-borne molecular signals such as LPS or cytokines, or to activated immune cells that prolong inflammation within SCI lesions and exacerbate tissue damage. Early inflammation after traumatic injury is beneficial and should not be inhibited (133), but prolonged inflammation has neurodegenerative potential (134). The several-week time frame after SCI during which multiple cell types interact and organize into mature lesions with discrete compartments $(5,13)$ presents a window for potential protective interventions to maximize the sparing of functional tissue.

Repair strategies to restore neural connectivity and functions. Neuroprotective interventions alone will not be sufficient after SCI. Repair strategies will be required to improve or restore lost functions. Approaches to SCI repair include modulation of circuit reorganization after incomplete SCI (Figure 3B) and bridging of axons across complete SCI (Figure 3C). Both approaches rely conceptually on observations that after SCI, descending supraspinal axons in corticospinal and reticulospinal tracts can sprout and make new functional contacts (refs. 22-24, 30, 32, 135-138; Figure 2; and Figure 3, B and C). Functional studies show that relay circuits formed between supraspinal pathways and descending propriospinal neurons can relay supraspinal commands that control voluntary locomotion in rodents (31), and can mediate fine finger movements in nonhuman primates (138-140). Such observations provide a rationale for repair strategies that seek either to augment spontaneous relay circuit formation and efficacy after incomplete SCI (Figure 3B), or to restore short-distance neural connectivity across anatomically complete SCI lesions (Figure 3C).

Beneficially modulating circuit reorganization in spared neural tissue. After SCI, substantial spontaneous synapse and circuit reorganization occurs in spared but reactive neural tissue (Figure 2 and Figure 3, A and B). Perineuronal nets constrain local synaptic plasticity and represent potential targets for therapeutic intervention. Enzymatic digestion of perineuronal net molecules or blockade of their neuronal receptors can augment task-specific rehabilitation after incomplete SCI $(99,102,108)$. Perineuronal reactive astrocytes promote re-formation of excitatory synaptic inputs after injury via a thrombospondin- and STAT3-dependent mechanism (126). Sprouting of descending supraspinal axons to form new relay connections after incomplete SCI can be augmented by local delivery of growth factors (141), by chronic electrical stimulation (142), or by the increasing of intrinsic neuron growth capacity by deletion of PTEN and SOCS3 (143). Strategies that combine chemical modulation of neural activity with epidural stimulation of lumbar locomotor centers have shown effi- cacy in restoring voluntary locomotor activity after incomplete SCI in rodents and humans (144-147). Such approaches have also shown benefit in regulating breathing (148) or autonomic functions such as bladder control (149). On the other hand, spontaneous synapse reorganization in spared but reactive neural tissue can lead to maladaptive consequences such as muscle spasticity (25), autonomic dysreflexia (26), or neuropathic pain $(27,28)$. More work is needed to understand mechanisms that drive maladaptive or adaptive synapse formation after SCI and how they can be beneficially modulated.

Reestablishing neural connections across anatomically complete SCI lesions. Anatomically complete lesions pose the biggest challenge to biological repair after SCI. Emerging repair strategies include facilitating the formation of new relay circuits either by endogenous axons or by grafted neurons that bridge lesions and connect into the distal propriospinal network (Figure 3C). Current evidence suggests that neural connections could be reestablished by combination of local delivery of axon chemoattractive factors and a growth supportive matrix with activation of intrinsic neuronal growth programs. Various means of reactivating neuron-intrinsic growth programs are emerging, including modulating specific genetic pathways (Figure 3A and discussed above), providing neuronal cell bodies with specific growth factors (150) or inflammatory factors $(51,55,151)$, or stimulating neuronal activity $(152)$. There is a growing list of chemoattractive growth factors that stimulate and guide regrowth of specific axons after SCI, including BDNF and NT3 for sensory axons $(19,88)$, GDNF for propriospinal axons (89), and IGF1 for corticospinal axons (153), as well as pleotropic growth factors such as FGF and EGF that act in beneficial but undefined ways (154-156). Modulating axonal cytoskeleton may improve growth cone formation and axon regeneration $(38,157$, 158). Biomaterials are being explored to deliver specific molecules and bridge neural connectivity across SCI lesions, as reviewed elsewhere $(19,159,160)$.

Cell grafts to bridge severe SCI lesions. Cell grafting after SCI has a long history comprehensively reviewed elsewhere (161, 162). In humans, anatomically complete lesions are dominated by large non-neural lesion cores (Figure $1 \mathrm{C}$ and ref. 6). Here, we briefly mention cell grafting strategies to repopulate non-neural lesion core with neuroglia that bridge host axons across the lesion, or to provide propriospinal relay neurons that receive host afferent input and relay information across the lesion to spared host neurons (Figure 3C). Repopulating non-neural lesion core with neuroglia may be required not only to provide axon regrowth-permissive substrates, but also to provide long-term support of regenerated axons or grafted neurons. Without glia, neuronal elements are unlikely to persist. Neuroglial cell grafts that can support host axon regrowth include Schwann cells $(89,161,163)$ and astroglia (59-61). Coaxing of axons to regrow past grafts into spared host tissue and form connections can be facilitated by chemoattractive growth factors (88). Regarding neuronal grafts, there is now elegant proof-of-principle evidence that transplanted embryonic neurons can integrate into and function in adult neocortical circuits (164). Embryonic neurons and neural stem cell-derived neurons and glia transplanted after SCI can repopulate non-neural lesion core and receive host inputs, and send extensive connections into host, some of which form functional connections (165-168). Host 
axons exhibit functionally appropriate preferences when forming contacts with grafted neurons (169). Injectable biomaterial carriers can improve graft survival by providing physically and/or chemically based protection $(61,159,160)$. Biomaterial carriers can also deliver molecules to guide neural stem cell maturation and integration with host neurons, and may facilitate translation of neural cell transplantation strategies (160).

\section{Concluding remarks}

Substantial advances have been made in identifying multicellular interactions and molecular mechanisms that shape the response to SCI. Mature SCI lesions exhibit three main tissue compartments: (a) central non-neural lesion cores, often referred to as fibrotic or mesenchymal scar, (b) narrow astroglial scar borders that intimately surround lesion cores, and (c) large surrounding zones of spared neural tissue that is functional but reactive. Each of these tissue compartments exhibits a unique cell biology, and deepening our understanding of their markedly different cellular and molecular interactions will be fundamental to developing rationally targeted repair strategies.

\section{Acknowledgments}

This work was supported by the NIH (NS057624 and NS084030 to MVS; F32 NS096858 to JEB), the Craig H. Neilsen Foundation (381357 to TMO), the Paralyzed Veterans of America Research Foundation, the Dr. Miriam and Sheldon G. Adelson Medical Foundation, and Wings for Life.

Address correspondence to: Michael V. Sofroniew, Department of Neurobiology, David Geffen School of Medicine, University of California, 10833 Le Conte Avenue, Los Angeles, California 90095-1763, USA. Phone:310.794.4944; Email: sofroniew@mednet.ucla.edu.
1. McDonald JW, Sadowsky C. Spinal-cord injury. Lancet. 2002;359(9304):417-425.

2. Anderson KD. Targeting recovery: priorities of the spinal cord-injured population. J Neurotrauma. 2004;21(10):1371-1383.

3. Gupta R, Bathen ME, Smith JS, Levi AD, Bhatia $\mathrm{NN}$, Steward O. Advances in the management of spinal cord injury. J Am Acad Orthop Surg. 2010;18(4):210-222.

4. Barres BA. The mystery and magic of glia: a perspective on their roles in health and disease. Neuron. 2008;60(3):430-440.

5. Burda JE, Sofroniew MV. Reactive gliosis and the multicellular response to CNS damage and disease. Neuron. 2014;81(2):229-248.

6. Norenberg MD, Smith J, Marcillo A. The pathology of human spinal cord injury: defining the problems. J Neurotrauma. 2004;21(4):429-440.

7. Hawkins LA, Devitt A. Current understanding of the mechanisms for clearance of apoptotic cells-a fine balance. JCell Death. 2013;6:57-68.

8. Soderblom C, et al. Perivascular fibroblasts form the fibrotic scar after contusive spinal cord injury. J Neurosci. 2013;33(34):13882-13887.

9. Göritz C, Dias DO, Tomilin N, Barbacid M, Shupliakov $\mathrm{O}$, Frisén J. A pericyte origin of spinal cord scar tissue. Science. 2011;333(6039):238-242.

10. Zhu Y, Soderblom C, Krishnan V, Ashbaugh J, Bethea JR, Lee JK. Hematogenous macrophage depletion reduces the fibrotic scar and increases axonal growth after spinal cord injury. Neurobiol Dis. 2015;74:114-125.

11. Fleming JC, et al. The cellular inflammatory response in human spinal cords after injury. Brain. 2006;129(pt 12):3249-3269.

12. Beck KD, Nguyen HX, Galvan MD, Salazar DL, Woodruff TM, Anderson AJ. Quantitative analysis of cellular inflammation after traumatic spinal cord injury: evidence for a multiphasic inflammatory response in the acute to chronic environment. Brain. 2010;133(pt 2):433-447.

13. Wanner IB, et al. Glial scar borders are formed by newly proliferated, elongated astrocytes that interact to corral inflammatory and fibrotic cells via STAT3-dependent mechanisms after spinal cord injury. J Neurosci. 2013;33(31):12870-12886.

14. Ren $Y$, et al. Ependymal cell contribution to scar formation after spinal cord injury is minimal, local and dependent on direct ependymal injury. Sci Rep. 2017;7:41122.

15. Sofroniew MV. Astrocyte barriers to neurotoxic inflammation. Nat Rev Neurosci. 2015;16(5):249-263.

16. Bush TG, et al. Leukocyte infiltration, neuronal degeneration, and neurite outgrowth after ablation of scar-forming, reactive astrocytes in adult transgenic mice. Neuron. 1999;23(2):297-308.

17. Faulkner JR, Herrmann JE, Woo MJ, Tansey KE, Doan NB, Sofroniew MV. Reactive astrocytes protect tissue and preserve function after spinal cord injury. J Neurosci. 2004;24(9):2143-2155.

18. Herrmann JE, et al. STAT3 is a critical regulator of astrogliosis and scar formation after spinal cord injury. J Neurosci. 2008;28(28):7231-7243.

19. Anderson MA, et al. Astrocyte scar formation aids central nervous system axon regeneration. Nature. 2016;532(7598):195-200.

20. Khakh BS, Sofroniew MV. Diversity of astrocyte functions and phenotypes in neural circuits. Nat Neurosci. 2015;18(7):942-952.

21. Raisman G. Neuronal plasticity in the septal nuclei of the adult rat. Brain Res. 1969;14(1):25-48.

22. Weidner N, Ner A, Salimi N, Tuszynski MH. Spontaneous corticospinal axonal plasticity and functional recovery after adult central nervous system injury. Proc Natl Acad Sci U S A. 2001;98(6):3513-3518.

23. Bareyre FM, Kerschensteiner M, Raineteau O, Mettenleiter TC, Weinmann O, Schwab ME. The injured spinal cord spontaneously forms a new intraspinal circuit in adult rats. Nat Neurosci. 2004;7(3):269-277.

24. Rosenzweig ES, et al. Extensive spontaneous plasticity of corticospinal projections after primate spinal cord injury. Nat Neurosci. 2010;13(12):1505-1510.

25. Roy RR, Edgerton VR. Neurobiological perspective of spasticity as occurs after a spinal cord injury. Exp Neurol. 2012;235(1):116-122.

26. Hou S, Rabchevsky AG. Autonomic consequences of spinal cord injury. Compr Physiol. 2014;4(4):1419-1453.

27. Tan AM, Waxman SG. Spinal cord injury, dendritic spine remodeling, and spinal memory mecha- nisms. Exp Neurol. 2012;235(1):142-151.

28. Kramer JL, Minhas NK, Jutzeler CR, Erskine EL, Liu LJ, Ramer MS. Neuropathic pain following traumatic spinal cord injury: Models, measurement, and mechanisms. J Neurosci Res. 2017;95(6):1295-1306.

29. Little JW, Halar E. Temporal course of motor recovery after Brown-Sequard spinal cord injuries. Paraplegia. 1985;23(1):39-46.

30. Ballermann M, Fouad K. Spontaneous locomotor recovery in spinal cord injured rats is accompanied by anatomical plasticity of reticulospinal fibers. Eur J Neurosci. 2006;23(8):1988-1996.

31. Courtine G, et al. Recovery of supraspinal control of stepping via indirect propriospinal relay connections after spinal cord injury. Nat Med. 2008;14(1):69-74.

32. Filli L, Zörner B, Weinmann O, Schwab ME. Motor deficits and recovery in rats with unilateral spinal cord hemisection mimic the Brown-Sequard syndrome. Brain. 2011;134(pt 8):2261-2273.

33. Tuszynski MH, Steward O. Concepts and methods for the study of axonal regeneration in the CNS. Neuron. 2012;74(5):777-791.

34. Schwab ME. Nogo and axon regeneration. Curr Opin Neurobiol. 2004;14(1):118-124.

35. Goldberg JL, Espinosa JS, Xu Y, Davidson N, Kovacs GT, Barres BA. Retinal ganglion cells do not extend axons by default: promotion by neurotrophic signaling and electrical activity. Neuron. 2002;33(5):689-702.

36. Goldberg JL. How does an axon grow? Genes Dev. 2003;17(8):941-958.

37. Goldberg JL, Klassen MP, Hua Y, Barres BA. Amacrine-signaled loss of intrinsic axon growth ability by retinal ganglion cells. Science. 2002;296(5574):1860-1864.

38. He Z, Jin Y. Intrinsic Control of Axon Regeneration. Neuron. 2016;90(3):437-451.

39. Bradke F, Fawcett JW, Spira ME. Assembly of a new growth cone after axotomy: the precursor to axon regeneration. Nat Rev Neurosci. 2012;13(3):183-193

40. Richardson PM, Issa VM. Peripheral injury enhances central regeneration of primary sensory neurones. Nature. 1984;309(5971):791-793.

41. Neumann S, Bradke F, Tessier-Lavigne M, Bas- 
baum AI. Regeneration of sensory axons within the injured spinal cord induced by intraganglionic cAMP elevation. Neuron. 2002;34(6):885-893.

42. Cai D, Shen Y, De Bellard M, Tang S, Filbin MT. Prior exposure to neurotrophins blocks inhibition of axonal regeneration by MAG and myelin via a cAMP-dependent mechanism. Neuron. 1999;22(1):89-101.

43. Cai D, Deng K, Mellado W, Lee J, Ratan RR, Filbin MT. Arginase I and polyamines act downstream from cyclic AMP in overcoming inhibition of axonal growth MAG and myelin in vitro. Neuron. 2002;35(4):711-719.

44. Lu P, Yang H, Jones LL, Filbin MT, Tuszynski MH. Combinatorial therapy with neurotrophins and cAMP promotes axonal regeneration beyond sites of spinal cord injury. J Neurosci. 2004;24(28):6402-6409.

45. Park KK, et al. Promoting axon regeneration in the adult CNS by modulation of the PTEN/mTOR pathway. Science. 2008;322(5903):963-966.

46. Liu K, et al. PTEN deletion enhances the regenerative ability of adult corticospinal neurons. Nat Neurosci. 2010;13(9):1075-1081.

47. Sun F, et al. Sustained axon regeneration induced by co-deletion of PTEN and SOCS3. Nature. 2011;480(7377):372-375.

48. Cheah M, Fawcett JW, Haenzi B. Differential regenerative ability of sensory motor neurons [published online ahead of print November 3, 2016]. Neurosci Lett. https://doi.org/10.1016/j.neulet.2016.11.004.

49. Omura T, et al. Robust Axonal Regeneration Occurs in the Injured CAST/Ei Mouse CNS. Neuron. 2015;86(5):1215-1227.

50. Chen M, et al. Leucine Zipper-bearing Kinase promotes axon growth in mammalian central nervous system neurons. Sci Rep. 2016;6:31482.

51. Benowitz LI, He Z, Goldberg JL. Reaching the brain: Advances in optic nerve regeneration. Exp Neurol. 2017;287(pt 3):365-373.

52. Sofroniew MV, Vinters HV. Astrocytes: biology and pathology. Acta Neuropathol. 2010;119(1):7-35.

53. Windle WF, Clemente CD, Chambers WW. Inhibition of formation of a glial barrier as a means of permitting a peripheral nerve to grow into the brain. J Comp Neurol. 1952;96(2):359-369.

54. Silver J, Miller JH. Regeneration beyond the glial scar. Nat Rev Neurosci. 2004;5(2):146-156.

55. de Lima S, et al. Full-length axon regeneration in the adult mouse optic nerve and partial recovery of simple visual behaviors. Proc Natl Acad Sci US A. 2012;109(23):9149-9154.

56. Frisén J, et al. Spinal axons in central nervous system scar tissue are closely related to laminin-immunoreactive astrocytes. Neuroscience. 1995;65(1):293-304.

57. Kawaja MD, Gage FH. Reactive astrocytes are substrates for the growth of adult CNS axons in the presence of elevated levels of nerve growth factor. Neuron. 1991;7(6):1019-1030.

58. Zukor K, Belin S, Wang C, Keelan N, Wang $\mathrm{X}, \mathrm{He} Z$. Short hairpin RNA against PTEN enhances regenerative growth of corticospinal tract axons after spinal cord injury. J Neurosci. 2013;33(39):15350-15361.

59. Davies JE, Huang C, Proschel C, Noble M, MayerProschel M, Davies SJ. Astrocytes derived from glial-restricted precursors promote spinal cord repair. J Biol. 2006;5(3):7.

60. Shih CH, Lacagnina M, Leuer-Bisciotti K, Pröschel C. Astroglial-derived periostin promotes axonal regeneration after spinal cord injury. J Neurosci. 2014;34(7):2438-2443.

61. Zhang S, et al. Thermoresponsive copolypeptide hydrogel vehicles for central nervous system cell delivery. ACS Biomater Sci Eng. 2015;1(8):705-717.

62. Brosius Lutz A, Barres BA. Contrasting the glial response to axon injury in the central and peripheral nervous systems. Dev Cell. 2014;28(1):7-17.

63. Mason CA, Edmondson JC, Hatten ME. The extending astroglial process: development of glial cell shape, the growing tip, and interactions with neurons. J Neurosci. 1988;8(9):3124-3134.

64. Raper J, Mason C. Cellular strategies of axonal pathfinding. Cold Spring Harb Perspect Biol. 2010;2(9):a001933.

65. Mokalled MH, Patra C, Dickson AL, Endo T, Stain ier DY, Poss KD. Injury-induced ctgfa directs glial bridging and spinal cord regeneration in zebrafish Science. 2016;354(6312):630-634.

66. Nishiyama A, Suzuki R, Zhu X. NG2 cells (polydendrocytes) in brain physiology and repair. Front Neurosci. 2014;8:133.

67. Dimou L, Gallo V. NG2-glia and their functions in the central nervous system. Glia. 2015;63(8):1429-1451.

68. Busch SA, et al. Adult NG2+ cells are permissive to neurite outgrowth and stabilize sensory axons during macrophage-induced axonal dieback after spinal cord injury. J Neurosci. 2010;30(1):255-265.

69. Filous AR, et al. Entrapment via synaptic-like connections between NG2 proteoglycan+ cells and dystrophic axons in the lesion plays a role in regeneration failure after spinal cord injury. J Neurosci. 2014;34(49):16369-16384.

70. Hackett AR, Lee JK. Understanding the NG2 glial scar after spinal cord injury. Front Neurol. 2016;7:199.

71. Jones LL, Sajed D, Tuszynski MH. Axonal regeneration through regions of chondroitin sulfate proteoglycan deposition after spinal cord injury: a balance of permissiveness and inhibition. $\mathrm{J} \mathrm{Neu}$ rosci. 2003;23(28):9276-9288.

72. Lu P, Jones LL, Tuszynski MH. Axon regeneration through scars and into sites of chronic spinal cord injury. Exp Neurol. 2007;203(1):8-21.

73. Yang Z, Suzuki R, Daniels SB, Brunquell CB, Sala CJ, Nishiyama A. NG2 glial cells provide a favorable substrate for growing axons. J Neurosci. 2006;26(14):3829-3839.

74. Hossain-Ibrahim MK, Rezajooi K, Stallcup WB, Lieberman AR, Anderson PN. Analysis of axonal regeneration in the central and peripheral nervous systems of the NG2-deficient mouse. BMC Neurosci. 2007;8:80.

75. Klapka N, Müller HW. Collagen matrix in spinal cord injury. J Neurotrauma. 2006;23(3-4):422-435.

76. Blesch A, Tuszynski MH. Transient growth factor delivery sustains regenerated axons after spinal cord injury. J Neurosci. 2007;27(39):10535-10545.

77. Horn KP, Busch SA, Hawthorne AL, van Rooijen N, Silver J. Another barrier to regeneration in the CNS: activated macrophages induce extensive retraction of dystrophic axons through direct physical interactions. J Neurosci. 2008;28(38):9330-9341.

78. Kurimoto T, et al. Neutrophils express oncomodulin and promote optic nerve regeneration. J Neurosci. 2013;33(37):14816-14824.

79. Tessier-Lavigne M, Goodman CS. The molecular biology of axon guidance. Science. 1996;274(5290):1123-1133.

80. Harel NY, Strittmatter SM. Can regenerating axons recapitulate developmental guidance during recovery from spinal cord injury? Nat Rev Neurosci. 2006;7(8):603-616.

81. Ming GL, Song HJ, Berninger B, Holt CE Tessier-Lavigne M, Poo MM. cAMP-dependent growth cone guidance by netrin-1. Neuron. 1997;19(6):1225-1235.

82. Lin AC, Holt CE. Local translation and directional steering in axons. EMBO J. 2007;26(16):3729-3736.

83. DePhillipe J, Jones EG. Cajal's degeneration and regeneration of the nervous system. Oxford and New York: Oxford University Press; 1991.

84. Richardson PM, McGuinness UM, Aguayo AJ. Axons from CNS neurons regenerate into PNS grafts. Nature. 1980;284(5753):264-265

85. David S, Aguayo AJ. Axonal elongation into peripheral nervous system "bridges" after central nervous system injury in adult rats. Science. 1981;214(4523):931-933.

86. Smith GV, Stevenson JA. Peripheral nerve grafts lacking viable Schwann cells fail to support central nervous system axonal regeneration. Exp Brain Res. 1988;69(2):299-306.

87. Hagg T, Gulati AK, Behzadian MA, Vahlsing HL, Varon S, Manthorpe M. Nerve growth factor promotes CNS cholinergic axonal regeneration into acellular peripheral nerve grafts. Exp Neurol. 1991;112(1):79-88.

88. Alto LT, Havton LA, Conner JM, Hollis ER, Blesch A, Tuszynski MH. Chemotropic guidance facilitates axonal regeneration and synapse formation after spinal cord injury. Nat Neurosci. 2009;12(9):1106-1113.

89. Deng LX, et al. A novel growth-promoting pathway formed by GDNF-overexpressing Schwann cells promotes propriospinal axonal regeneration, synapse formation, and partial recovery of function after spinal cord injury. J Neurosci. 2013;33(13):5655-5667.

90. Plantman S, et al. Integrin-laminin interactions controlling neurite outgrowth from adult DRG neurons in vitro. Mol Cell Neurosci. 2008;39(1):50-62.

91. Edwards TJ, Hammarlund M. Syndecan promotes axon regeneration by stabilizing growth cone migration. Cell Rep. 2014;8(1):272-283.

92. Farhy Tselnicker I, Boisvert MM, Allen NJ. The role of neuronal versus astrocyte-derived heparan sulfate proteoglycans in brain development and injury. Biochem Soc Trans. 2014;42(5):1263-1269.

93. Masu M. Proteoglycans and axon guidance: a new relationship between old partners. J Neurochem. 2016;139(suppl 2):58-75.

94. Baier H, Bonhoeffer F. Axon guidance by gradients of a target-derived component. Science. 1992;255(5043):472-475

95. Tom VJ, Steinmetz MP, Miller JH, Doller CM, Sil ver J. Studies on the development and behavior of the dystrophic growth cone, the hallmark of regeneration failure, in an in vitro model of the 
glial scar and after spinal cord injury. J Neurosci. 2004;24(29):6531-6539.

96. Hollis ER. Axon guidance molecules and neural circuit remodeling after spinal cord injury. Neurotherapeutics. 2016;13(2):360-369.

97. Hollis ER, et al. Remodelling of spared proprioceptive circuit involving a small number of neurons supports functional recovery. Nat Commun. 2015;6:6079.

98. Lee JK, Chow R, Xie F, Chow SY, Tolentino KE, Zheng B. Combined genetic attenuation of myelin and semaphorin-mediated growth inhibition is insufficient to promote serotonergic axon regeneration. J Neurosci. 2010;30(32):10899-10904.

99. Schwab ME, Strittmatter SM. Nogo limits neural plasticity and recovery from injury. Curr Opin Neurobiol. 2014;27:53-60.

100.Caroni P, Schwab ME. Antibody against myelin-associated inhibitor of neurite growth neutralizes nonpermissive substrate properties of CNS white matter. Neuron. 1988;1(1):85-96.

101.Lang BT, et al. Modulation of the proteoglycan receptor PTP $\sigma$ promotes recovery after spinal cord injury. Nature. 2015;518(7539):404-408.

102. Mironova YA, Giger RJ. Where no synapses go: gatekeepers of circuit remodeling and synaptic strength. Trends Neurosci. 2013;36(6):363-373.

103. Andrews EM, Richards RJ, Yin FQ, Viapiano MS, Jakeman LB. Alterations in chondroitin sulfate proteoglycan expression occur both at and far from the site of spinal contusion injury. Exp Neurol. 2012;235(1):174-187.

104.Wang D, Fawcett J. The perineuronal net and the control of CNS plasticity. Cell Tissue Res. 2012;349(1):147-160.

105. Zheng B, Ho C, Li S, Keirstead H, Steward O, Tessier-Lavigne M. Lack of enhanced spinal regeneration in Nogo-deficient mice. Neuron. 2003;38(2):213-224.

106.Lee JK, et al. Assessing spinal axon regeneration and sprouting in Nogo-, MAG-, and OMgpdeficient mice. Neuron. 2010;66(5):663-670.

107. Bradbury EJ, et al. Chondroitinase $\mathrm{ABC}$ promotes functional recovery after spinal cord injury. Nature. 2002;416(6881):636-640.

108. García-Alías G, Barkhuysen S, Buckle M, Fawcett JW. Chondroitinase ABC treatment opens a window of opportunity for task-specific rehabilitation. Nat Neurosci. 2009;12(9):1145-1151.

109. Kreutzberg GW. Microglia: a sensor for pathological events in the CNS. Trends Neurosci. 1996;19(8):312-318

110.Stevens B, et al. The classical complement cascade mediates CNS synapse elimination. Cell. 2007;131(6):1164-1178.

111. Schafer DP, et al. Microglia sculpt postnatal neural circuits in an activity and complement-dependent manner. Neuron. 2012;74(4):691-705.

112. Hong S, Stevens B. Microglia: phagocytosing to clear, sculpt, and eliminate. Dev Cell. 2016;38(2):126-128.

113. Paolicelli RC, et al. Synaptic pruning by microglia is necessary for normal brain development. Science. 2011;333(6048):1456-1458.

114. Ben Haim L, Rowitch DH. Functional diversity of astrocytes in neural circuit regulation. Nat Rev Neurosci. 2017;18(1):31-41.

115. Clarke LE, Barres BA. Emerging roles of astro- cytes in neural circuit development. Nat Rev Neurosci. 2013;14(5):311-321.

116. Kucukdereli H, et al. Control of excitatory CNS synaptogenesis by astrocyte-secreted proteins Hevin and SPARC. Proc Natl Acad Sci U S A. 2011;108(32):E440-E449.

117. Christopherson KS, et al. Thrombospondins are astrocyte-secreted proteins that promote CNS synaptogenesis. Cell. 2005;120(3):421-433.

118. Allen NJ, et al. Astrocyte glypicans 4 and 6 promote formation of excitatory synapses via GluA1 AMPA receptors. Nature. 2012;486(7403):410-414.

119. Eroglu C, Barres BA. Regulation of synaptic connectivity by glia. Nature. 2010;468(7321):223-231.

120. Chung WS, Allen NJ, Eroglu C. Astrocytes Control Synapse Formation, Function, and Elimination. Cold Spring Harb Perspect Biol. 2015;7(9):a020370.

121. Molofsky AV, et al. Astrocyte-encoded positional cues maintain sensorimotor circuit integrity. Nature. 2014;509(7499):189-194.

122. Chung WS, et al. Astrocytes mediate synapse elimination through MEGF10 and MERTK pathways. Nature. 2013;504(7480):394-400.

123. Burda JE, Bernstein AM, Sofroniew MV. Astrocyte roles in traumatic brain injury. Exp Neurol. 2016;275 Pt 3:305-315.

124. Deller T, Haas CA, Naumann T, Joester A, Faissner A, Frotscher M. Up-regulation of astrocyte-derived tenascin-C correlates with neurite outgrowth in the rat dentate gyrus after unilateral entorhinal cortex lesion. Neuroscience. 1997;81(3):829-846.

125. Haas CA, Rauch U, Thon N, Merten T, Deller T. Entorhinal cortex lesion in adult rats induces the expression of the neuronal chondroitin sulfate proteoglycan neurocan in reactive astrocytes. J Neurosci.1999;19(22):9953-9963.

126. Tyzack GE, et al. Astrocyte response to motor neuron injury promotes structural synaptic plasticity via STAT3-regulated TSP-1 expression. Nat Commun. 2014;5:4294.

127. Pizzorusso T, Medini P, Berardi N, Chierzi S, Fawcett JW, Maffei L. Reactivation of ocular dominance plasticity in the adult visual cortex. Science. 2002;298(5596):1248-1251.

128. Failli V, et al. Functional neurological recovery after spinal cord injury is impaired in patients with infections. Brain. 2012;135(pt 11):3238-3250.

129. Schwab JM, Zhang Y, Kopp MA, Brommer B, Popovich PG. The paradox of chronic neuroinflammation, systemic immune suppression, autoimmunity after traumatic chronic spinal cord injury. Exp Neurol. 2014;258:121-129.

130. Brommer B, et al. Spinal cord injury-induced immune deficiency syndrome enhances infection susceptibility dependent on lesion level. Brain. 2016;139(pt 3):692-707.

131. Zamanian JL, et al. Genomic analysis of reactive astrogliosis. J Neurosci. 2012;32(18):6391-6410.

132. Liddelow SA, et al. Neurotoxic reactive astrocytes are induced by activated microglia. Nature. 2017;541(7638):481-487.

133. Russo MV, McGavern DB. Inflammatory neuroprotection following traumatic brain injury. Science. 2016;353(6301):783-785.

134. Ransohoff RM. How neuroinflammation contributes to neurodegeneration. Science.
2016;353(6301):777-783.

135. Fenrich KK, Rose PK. Spinal interneuron axons spontaneously regenerate after spinal cord injury in the adult feline. J Neurosci. 2009;29(39):12145-12158.

136. Flynn JR, Graham BA, Galea MP, Callister RJ. The role of propriospinal interneurons in recovery from spinal cord injury. Neuropharmacology. 2011;60(5):809-822.

137. Takeoka A, Vollenweider I, Courtine G, Arber S. Muscle spindle feedback directs locomotor recovery and circuit reorganization after spinal cord injury. Cell. 2014;159(7):1626-1639.

138. Tohyama T, et al. Contribution of propriospinal neurons to recovery of hand dexterity after corticospinal tract lesions in monkeys. Proc Natl Acad Sci U S A. 2017;114(3):604-609.

139. Nishimura Y, Onoe H, Morichika Y, Perfiliev S, Tsukada H, Isa T. Time-dependent central compensatory mechanisms of finger dexterity after spinal cord injury. Science. 2007;318(5853):1150-1155.

140. Alstermark B, Isa T. Circuits for skilled reaching and grasping. Annu Rev Neurosci. 2012;35:559-578.

141. Vavrek R, Girgis J, Tetzlaff W, Hiebert GW, Fouad K. BDNF promotes connections of corticospinal neurons onto spared descending interneurons in spinal cord injured rats. Brain. 2006;129(pt 6):1534-1545.

142. Carmel JB, Berrol LJ, Brus-Ramer M, Martin JH. Chronic electrical stimulation of the intact corticospinal system after unilateral injury restores skilled locomotor control and promotes spinal axon outgrowth. J Neurosci. 2010;30(32):10918-10926.

143. Jin D, Liu Y, Sun F, Wang X, Liu X, He Z. Restoration of skilled locomotion by sprouting corticospinal axons induced by co-deletion of PTEN and SOCS3. Nat Commun. 2015;6:8074.

144. Courtine G, et al. Transformation of nonfunctional spinal circuits into functional states after the loss of brain input. Nat Neurosci. 2009;12(10):1333-1342.

145. Harkema S, et al. Effect of epidural stimulation of the lumbosacral spinal cord on voluntary movement, standing, and assisted stepping after motor complete paraplegia: a case study. Lancet. 2011;377(9781):1938-1947.

146.van den Brand R, et al. Restoring voluntary control of locomotion after paralyzing spinal cord injury. Science. 2012;336(6085):1182-1185.

147. Angeli CA, Edgerton VR, Gerasimenko YP, Harkema SJ. Altering spinal cord excitability enables voluntary movements after chronic complete paralysis in humans. Brain. 2014;137(pt 5):1394-1409.

148. Hormigo KM, et al. Enhancing neural activity to drive respiratory plasticity following cervical spinal cord injury. Exp Neurol. 2017;287(pt 2):276-287.

149. Gad PN, Roy RR, Zhong H, Gerasimenko YP, Taccola G, Edgerton VR. Neuromodulation of the neural circuits controlling the lower urinary tract. Exp Neurol. 2016;285(pt B):182-189.

150. Bei F, et al. Restoration of visual function by enhancing conduction in regenerated axons. Cell. 2016;164(1-2):219-232.

151. Benowitz LI, Popovich PG. Inflammation and axon regeneration. Curr Opin Neurol. 2011;24(6):577-583.

152. $\mathrm{Lim} \mathrm{JH}$, et al. Neural activity promotes long-distance, target-specific regeneration of adult reti- 
nal axons. Nat Neurosci. 2016;19(8):1073-1084. 153. Ozdinler PH, Macklis JD. IGF-I specifically enhances axon outgrowth of corticospinal motor neurons. Nat Neurosci. 2006;9(11):1371-1381.

154. Rabchevsky AG, Fugaccia I, Fletcher-Turner A, Blades DA, Mattson MP, Scheff SW. Basic fibroblast growth factor (bFGF) enhances tissue sparing and functional recovery following moderate spinal cord injury. J Neurotrauma. 1999;16(9):817-830.

155. White RE, Rao M, Gensel JC, McTigue DM, Kaspar BK, Jakeman LB. Transforming growth factor $\alpha$ transforms astrocytes to a growth-supportive phenotype after spinal cord injury. J Neurosci. 2011;31(42):15173-15187.

156. White RE, Yin FQ, Jakeman LB. TGF-alpha increases astrocyte invasion and promotes axonal growth into the lesion following spinal cord injury in mice. Exp Neurol. 2008;214(1):10-24.

157. Hellal F, et al. Microtubule stabilization reduces scarring and causes axon regeneration after spinal cord injury. Science. 2011;331(6019):928-931.

158. Ruschel J, et al. Axonal regeneration. Systemic administration of epothilone $B$ promotes axon regeneration after spinal cord injury. Science. 2015;348(6232):347-352.

159. Elliott Donaghue I, Tam R, Sefton MV, Shoichet MS. Cell and biomolecule delivery for tissue repair and regeneration in the central nervous system. J Control Release. 2014;190:219-227.

160.O'Shea TM, Wollenberg AL, Bernstein AM, Sarte DB, Deming TJ, Sofroniew MV. Smart materials for central nervous system cell delivery and tissue engineering. In: Wang Q, ed. Smart materials for tissue engineering applications. Croydon, United Kingdom: Royal Society of Chemistry; 2017:529-557.

161. Tetzlaff W, et al. A systematic review of cellular transplantation therapies for spinal cord injury. J Neurotrauma. 2011;28(8):1611-1682.

162.Bonner JF, Steward O. Repair of spinal cord injury with neuronal relays: From fetal grafts to neural stem cells. Brain Res. 2015;1619:115-123.

163. Pearse DD, et al. cAMP and Schwann cells promote axonal growth and functional recovery after spinal cord injury. Nat Med. 2004;10(6):610-616.

164. Falkner S, et al. Transplanted embryonic neurons integrate into adult neocortical circuits. Nature. 2016;539(7628):248-253.

165. Abematsu M, et al. Neurons derived from transplanted neural stem cells restore disrupted neuronal circuitry in a mouse model of spinal cord injury. J Clin Invest. 2010;120(9):3255-3266.

166. Bonner JF, Connors TM, Silverman WF, Kowalski DP, Lemay MA, Fischer I. Grafted neural progenitors integrate and restore synaptic connectivity across the injured spinal cord. J Neurosci. 2011;31(12):4675-4686.

167. Lu P, et al. Long-distance growth and connectivity of neural stem cells after severe spinal cord injury. Cell. 2012;150(6):1264-1273.

168. Kadoya K, et al. Spinal cord reconstitution with homologous neural grafts enables robust corticospinal regeneration. Nat Med.2016;22(5):479-487.

169.Dulin JN, Adler AF, Kumamaru H, Tuszynski MH. Cellular mechanisms influencing corticospinal and sensory axonal regeneration into neural stem cell grafts after spinal cord injury. Program No. 522.01. Poster presented at: Neuroscience Meeting Planner: Society for Neuroscience; November 15, 2016; San Diego, CA. 